Article

\title{
Fostering innovation through Industry 4.0 technologies in emerging countries: An explorative multiple case study of Indonesian Internet-of-Things (IoT)-based start-ups
}

\author{
Tribowo Rachmat Fauzan $^{1 *}$ and Wawan Dhewanto ${ }^{1}$ \\ 1 School of Business and Management, Institut Teknologi Bandung, Bandung, Indonesia \\ * Correspondence: tribowo-rachmat@sbm-itb.ac.id
}

Received: 10 February 2021; Accepted: 28 April 2021; Published: 30 April 2021

\begin{abstract}
The Industry 4.0 phenomenon is truly remarkable in the industry's redesign and the transformation of different facets of human life. This trend has also been put on several nations' national agenda, both emerging and developed, to improve competition in the global business arena. For Indonesia, this phenomenon offers a chance to reshape Indonesia's manufacturing industry and become another way to boost Indonesia's goal of being the 10th world's largest economy. One of the technologies that play a significant role in this phenomenon is Internet-of-Things (IoT) that could boost small businesses' performance through developing its innovation ecosystem. This research seeks to propose continuous innovation pathways through case studies of functional IoT in Indonesian start-ups. To this end, we use an exploratory research methodology and in-depth interviews to identify IoT and case studies' fundamental innovation capabilities to explore the process of connecting these attributes to innovation. It results in five factors as main findings to influence the innovation performance: financial resources, government role, perception for supporting small businesses, hybrid research and development, and business model innovation. We also derive the implication of IoT for businesses and the government to support their innovation.
\end{abstract}

Keywords: Case study; Indonesia; Innovation; Internet-of-Things; IoT; Start-ups

JEL codes: $\mathrm{M} 13 ; \mathrm{O} 32 ; \mathrm{O} 33$

\section{Introduction}

The Industrial Revolution 4.0 is mostly affecting the production system and witnessed by shifting the model from massive digitalization of manufacturing. For example, the shifting from programmable logic controllers (which characterizes industry 3.0) to smart devices enables the consumers to decide their production processes. In other words, the digitalization systems of manufacturing itself converge with the usage concept of the Internet of Things (IoT) (Lasi, Fettke, Kemper, Feld, \& Hoffmann, 2014; Zaidi \& Belal, 2019). The Industrial Revolution 4.0 itself already penetrated smaller businesses in many areas such as security system (Ammirato, Sofo, Felicetti, \& Raso, 2019), housing/property (Burke, O'Callaghan, \& Quigley, 2013; Quigley \& Burke, 2013), retail (Balaji \& Roy, 2017), healthcare (Tuan, Thanh, \& Tuan, 2019) and many more.

The IoT is expected to play an essential role in developing businesses or industries and prospective management and growth. (Lee \& Lee, 2015; Suppatvech, Godsell, \& Day, 2019). In this Industrial Revolution 4.0, the conventional processing tools and techniques will be discarded under the fierce demand for high efficiency and customizable products. To follow the intellectual, 
informative, digital, and automated production style, businesses must change their current operational and cost-saving production mode ( $\mathrm{Li}, \mathrm{Hou}, \& \mathrm{Wu}, 2017)$. McKinsey's recent report also stated that 18.2 billion computers were connecting to the internet by 2015 in Indonesia only. This number predicted to rise three-fold, to 50 billion, by 2020. More connected and remotely operated systems are encouraged by cheaper sensors and actuators and quicker, reliable internet connectivity. Combined with mobile internet, cloud technology, and big data analytics, IoT will become the primary foundation for the Indonesian digital revolution. Furthermore, this next digitization level will accelerate Indonesia's economic growth of $\$ 150$ billion per year by 2025. (Das, Gryseels, Sudhir, \& Tan, 2016).

Indonesia has been actively supporting the development of the IoT and advanced ICT technologies (3D printing, Artificial Intelligence / A.I., and robotics) via the Indonesian Kementerian Perindustrian (Ministry of Industry) 's program "Making Indonesia 4.0", which was initiated in 2018 to keep this global trend on track (Kemenperin, 2018). A similar program was also developed to boosting the IoT program to support small businesses in other countries such as Korea (initiated in 2015) and Malaysia (initiated in 2014) (Shin, 2017; Zaidi and Belal, 2019). However, a recent report titled 'Global Innovation Index 2020' also mentioned that Indonesia ranks 85 out of 131 countries in innovation. The report indicates that Indonesia lacks knowledge workers who could make the innovation useful and the regulatory environment, which does not support the innovative ecosystem (Word Intellectual Property Organization, 2020).

Companies such as start-ups are seeking to penetrate an existing market or, at times, are opening up a new market with innovative products or services and are essential to the economy of Indonesia (Nurcahyo, Akbar, \& Gabriel, 2018; Stubner, Wulf, \& Hungenberg, 2007). However, In 2015 twenty start-ups located in Asia that were counterproductive need to be shut down, although some creditors have funded them, and six businesses were also scheduled to close in 2017 (Maulana, Sucahyo, Ruldeviyani, \& Gandhi, 2019). The lack of technology innovation, collaborative R\&D, and networking for technology and market intelligence collection has proved to be a critical point for profitable and sustainable small businesses like start-ups. They are the main points why start-ups fail even got many funds. (Maulana et al., 2019; Shin, 2017). The lack of technology innovation was also hinted at by a recent report titled 'Global Innovation Index 2020', which mentioned that Indonesia ranks 85 out of 131 countries in innovation. The report indicates that Indonesia lacks knowledge workers who could make the innovation useful and the regulatory environment, which does not support the innovative ecosystem (Word Intellectual Property Organization, 2020).

To overcome this situation, the Indonesian government, via its Ministry of Industry, created a platform called "Startup4Industry" to accelerating start-ups as 'technology problem solvers' for industries and society. This platform also acts as the ecosystem for start-ups with Industry 4.0 technology (startup4industry, 2020). High technology deployment, like IoT, hopefully, can be considered the source of innovation in small businesses like start-ups; therefore, the existence of IoTbased start-ups will act as a source for innovation and finally become beneficial for the Indonesian economy (Mercandetti, Larbig, Tuozzo, \& Steiner, 2017; Shin, 2017).

However, even the start-ups operate in the same area, the different experiences they had will affect how they innovate and monetize their innovations (Raatikainen et al., 2016). Since the research regarding IoT-based start-ups' experience is scarce, this study aims to analyze the conceptual definitions, attributes, and implications of the IoT industry with an exploratory study carried out by Indonesian IoT-based start-ups that link these innovation attributes and have achieved growth. This research may be helpful for new IoT-based industries, especially in small businesses in Indonesia. This paper's structure is organized accordingly: The literature review section mainly provides an overview of the definitions and current research in IoT, start-ups, and their innovation path. In the Research Methodology section, the method when conducting this research is explained. In the Results and Discussion section, the frameworks of IoT-based start-ups' innovation are explained. Finally, the conclusion of this research and future research directions are discussed.

The research's primary purpose is to investigate the start-up condition that adopts Internet-ofThings technology in Indonesia to innovate. Moreover, we would suggest a higher possibility for start- 
ups to thrive. The following research question must be answered in order to serve the primary purpose of the research:

"How are the conditions of the start-ups in Indonesia, which adopting Internet-of-Things technology, that will foster their innovation?"

\section{Literature Review}

\subsection{Internet-of-Things}

Kevin Ashton explained the first term of Internet-of-Things (IoT) in 1999 by explaining that the IoT as unique and operable connected things/objects identifiable with RFID (radio frequency identification) technology to help firm resolve supply chain problems; however, the IoT definition varies among different researchers and organizations (Ashton, 2009; Li, Xu, \& Zhao, 2015; Shin, 2017). To overcome these differences, researchers then conclude three main points to describe IoT; worldwide connected objects, integrated communication networks, and integrated global network structures that involve physical attributes (Lu, Papagiannidis, \& Alamanos, 2018).

The network is the IoT's backbone. It refers to objects (things) that are unique and virtually identifiable in an Internet-like way. Network technology moves to unexpected wireless, free communication technology that enables more flexible deployment of device-to-device applications. Network technology is transforming into an autonomous network that is aware of the context (Lee \& Lee, 2015). IoT components include the technology elements (software, hardware, connection, data, standardization, and platform), the social elements (human, non-human, physical surrounding), and the socio-economic elements (consumers, policymakers, associations from industry, consumer protection, entrepreneurs) (Krotov, 2017). Business is one of the areas significantly affected by IoT's emergence, particularly altering business models on an industrial-scale and a smaller business scale (Kiel, Arnold, \& Voigt, 2017; Müller, 2019).

Most technology companies build IoT systems to assist businesses in the accelerated deployment and development of IoT technologies, which leads to boost their market. These platforms became a critical source for companies that did not employ engineers from different IoT sectors. In IoT systems, a range of business applications can be developed without costly, long-term design and development activities, with simple functionalities and evolving tools by aligning three main factors of the business model in IoT; value proposition, customer relationship, and critical partnership (Dijkman, Sprenkels, Peeters, \& Janssen, 2015; Lee, 2019). The business case relates to all of the three elements above, especially the socio-economic environment; therefore, more research about IoT in an emerging business context is still needed to understand complex and systemic business model innovation (Krotov, 2017; Leminen, Rajahonka, Wendelin, \& Westerlund, 2020).

\subsection{Start-up}

Nowadays, many young companies arise and have gone tremendous fast, like Mark Zuckerberg on his Facebook, and others are on the verge of coming. Another Silicon Valley has been developed worldwide to cope with the influx of young businesses and start-ups (Dwianto \& Dhewanto, 2015). In many cases, start-ups are seen as newly established companies of innovative young people in the backyard, creating simple handheld applications and high technology devices. However, there is plenty of definition in explaining start-ups, but the more acceptable concept of a start-up defined as "a temporary company searching for a viable, profitable and repeatable business model." (Blank \& Dorf, 2012; Melegati, Goldman, \& Paulo, 2016; Mercandetti, Larbig, Tuozzo, \& Steiner, 2017). Compared to established firms that operated in a well-known market intending to optimize an efficient operational execution, start-ups are always searching for a business idea and operate in search mode, creating something from nothing (Brikman, 2016; Blank \& Dorf, 2012). Start-ups also act as the source of innovation since they use new technologies to invent products/services and reinvent business models. Corporations that adopt a strategy called open innovation see start-ups as a source of external 
innovation even more. Therefore, start-ups cannot be separated from their innovative process and results (Kohler, 2016; Melegati et al., 2016).

\subsection{Start-up Innovation Path}

The innovation path can be understood at the sectoral level as a technological journey. The origin of the innovation path is rooted in evolutionary economics, which elaborates the technological innovation path is collective and self-strengthening since the current infrastructures, organizations/institutions, and capabilities continue to affect them (Dosi, 1982). Therefore, innovations are path-dependence because they are built on previous technologies, experiences, and competition strategies. (Lema, Sagar, \& Zhou, 2016). Innovation path can be utilized as a toolset to detect potential developments in emerging fields by collecting endogenous future clear signs from a specific technology (Robinson, Lagnau, \& Boon, 2019). The innovation path in a small business context like start-ups can show how various mechanisms such as internal start-up, component subsidiary, or incubating subsidiary in each company can be utilized within an innovation program (Raatikainen et al., 2016).

Since the start-up market is characterized by uncertainty because it is an entirely new business, the operating period is long and uncertain since it has no data and no experience, making companies high mortality risk for the first years of their operations. These companies' main task is to stay innovative in product or service creativity and its management processes. Those are how new products or technology often render particular business functions significant (Moroni, Arruda, \& Araujo, 2015).

There are various ways to achieve the aim of enhanced business success. Companies can take various paths of innovation. Companies may also introduce emerging technology related to goods, introduce modern manufacturing processes, and set innovative business concepts and develop future products. Those should differentiate the two major categories of innovation development across product and process innovation (Kirner, Kinkel, \& Jaeger, 2009). To ensure its long-term market growth, all corporations, including small businesses, must keep their technology portfolios updated. Mainly due to the revolution of the newest phenomenon called "Internet of Things," businesses will need to analyze technology they have never noticed or little understanding of before (Ghobakhloo \& Ching, 2019; Prince, Barrett, \& Oborn, 2014).

Moreover, new technologies must be introduced more rapidly and continuously than ever before to unleash their maximum potential (Mercandetti et al., 2017). The potential of new technology can be achieved through its innovation path. (Robinson et al., 2019) Each country's technological innovation path may differ due to the difference in Research and Development (R\&D) capacities. For example, Chinese wind turbine industries have taken a different path than European countries since their R\&D capacities are relatively smaller than European countries (Dai, Xia, Zhou, \& Xue, 2014). The innovation path in the same business area in start-ups may differ as they tend to take different pathways to make their minimum viable product (Raatikainen et al., 2016). Therefore, more research about the current condition and technological innovation in smaller businesses like start-ups in the countries' different contexts is needed.

\section{Data and Methods}

\subsection{Research Design and Strategy}

This study explores initial conditions that influence Indonesian start-ups that adopt Internet-ofThings (IoT) as their core of the business and technological innovation, either as the primary user or as a service provider. It indicates that a start-up needs innovate to succeed in the environment of business. Interpretivism philosophy and inductive approach are applied in this research; semistructured interviews are used to collect data from professionals via thematic analysis. A total of ten start-up executives are interviewed to gather data for this research. The authors opted to use an inductive research strategy for this research. So far, the idea of innovation for start-ups in developing countries such as Indonesia is somewhat undiscovered. The selection of research design is thus 
justified by a suggestion from Saunders, Lewis, \& Thornhill (2009), indicating that since research is new and relatively undeveloped, an inductive approach is acceptable.

As this study is exploratory, we seek to gain viewpoints and gain inside perspectives that explain typical patterns from a comparatively small sample, rather than obtaining numerical data from a larger sample. By performing multiples qualitative case studies, the approach is to collect comprehensive information. The explanation for doing a qualitative analysis is that in contrast to a quantitative study that focuses on "how many," it focuses on "how" and "why" (Creswell, 2007). The authors chose multiple case studies in order to find answers to the research questions. One explanation for this is that when qualitative study strategies are chosen, and the research aims are exploratory, case studies are deemed acceptable (Saunders et al., 2009). We also collect data from a secondary source such as a government website, start-ups' official webpage, and expert's opinion published in a particular indexed journal to supplement our findings regarding innovation in IoT-based start-ups.

To examine the qualitative data at hand and discover the themes or theory, the case study technique was introduced as the most appropriate tool. This technique also helps one reflect on the complexities inherent in single settings (Eisenhardt, 1989), which are IoT-based start-ups in our analysis. To identify discrepancies between cases and similarities and differences within cases that help reproduce the results between cases, multiple cases have been studied (Yin, 2003). Yin (2003) explains the mechanism of using multiple case studies as; predicting identical outcomes or predicting contrasting results but for predictable causes. Even if it was incredibly time-consuming and costly to perform, authors used both approaches to provide rigorous and accurate analysis. Their empiric insights and concepts are expanded through an in-depth interview. After the interview was conducted, we generate several codes and iterate them into themes related to the research question.

\subsection{Data Collection}

The primary data source for this innovation and condition of IoT-based start-ups is interviews with its CEO or current executives. To be more specific, the potential IoT-based businesses are chosen the private start-ups established a minimum of one year located in Indonesia. We use those assumptions because of the CEOs or executives' expectations who have innovation jurisdiction in their companies.

At first, we seek the IoT-based start-ups from the webpage "startup4industry.id" since it is the leading official ecosystem that bridges the start-ups which implement industrial technology to solve a societal problem. We purposively choose start-ups using IoT as their core business by clicking each start-ups profile page. After listing all of the IoT-based start-ups on the website, which resulted in 23 start-ups, we contacted them via their social media and e-mail, informing them that the authors want to ask their permission to become respondents to this research. We also stated the purpose and objectives of the research before got respondents' permission. From 23 start-ups, only three responded and willing to be interviewed for this research.

We continued to search IoT-based start-ups outside the abovementioned website by searching established start-ups in a local business incubator. The local business incubator located inside Institut Teknologi Bandung (ITB) is called Lembaga Pengembangan Inovasi dan Kewirausahaan (LPIK) or Institute for Innovation \& Entrepreneurship Development. This incubator provided information and a channel to connect the authors and IoT-based start-ups located in Bandung city, West Java. Total three startups developed from this business incubator agreed to become respondents of this research. Four startups were also mentioned and suggested by LPIK to authors to be contacted, but LPIK only gives the name of start-ups because they did not have the channel to them. Finally, the four remaining start-ups mentioned by LPIK were also contacted by us by searching their name on the search engine website and contacted them via e-mail. Total 10 (ten) start-ups agreed to become this research's respondents, and they are also given information about this research purpose and objectives before conducting the interview. The start-ups' name is later kept secret to prevent any information leak since this research confronts their business strategy. 
Table 1. Interviewee List

\begin{tabular}{cccc}
\hline $\begin{array}{c}\text { Start-up } \\
\text { Pseudonym }\end{array}$ & Business Type & Business Sector & $\begin{array}{c}\text { Participant's Role in } \\
\text { Start-up }\end{array}$ \\
\hline S1 & IoT service provider & Manufacture & $\begin{array}{c}\text { Business Development } \\
\text { Manager }\end{array}$ \\
\hline S2 & IoT user & Agriculture & $\begin{array}{c}\text { Founder / CEO (Chief } \\
\text { Executive Officer) }\end{array}$ \\
\hline S3. & IoT user & Agriculture & Co-Founder \\
\hline S4 & IoT user & Hospitality & Founder / CEO \\
\hline S5 & IoT user & Hospitality & CTO (Chief Technology \\
Officer)
\end{tabular}

\subsection{Data Analysis}

In this study, after all the interviews ended, we typed the transcript immediately and sent them to an interpreter to translate it into English. We also double-checked and sent back the transcripts to the respondents to ensure the transcripts did not contain confidential information regarding their business. The data analysis was then conducted by analyzing the transcripts to assess the condition and innovation in IoT-based start-ups. The data gathered were categorized and analyzed it a specific theme according to the path of the innovation in various stages. The study also defines the problems/challenges according to the path of progress in these stages. The results then contrasted with the research question and the concepts of innovation in the literature to include the correct recommendation on IoT-based start-ups' innovation path.

The quality of the research will be addressed in this section. The quality of a case study can be measured, according to Yin (2003), using the following validity and reliability element.

Yin (2003) notes that using several evidence sources, creating a chain of evidence, and making the research checked by informants are all techniques in a case study to improve its construct validity. To increase the construct validity of the analysis, both of these methods were used. Measures for frameworks or themes could be connected from multiple viewpoints by questioning a varied range of top-management employees within the start-ups, thereby raising the construct's validity. More construct validity could also be defined by using the two different data resources, semi-structured interviews and secondary data, as data obtained with the individual approach could be contrasted to each other.

How reliable research is concerned with reliability (Yin, 2003). The study's internal reliability is considered reasonably good. At the interview, all interviewers were present, and information was also communicated to each researcher in the same manner. A discussion was conducted after every interview to ensure the knowledge was interpreted coherently. The fact that all interviews were documented and transcribed has helped to boost the study's internal reliability.

All participants were required to sign a Voluntary Consent Form in compliance with what was an ethical clearance, in which all relevant information on study, goals, background, methodology, business' confidentiality and individual identities and the voluntary nature of participation was given, and the participant promptly signed and returned the paper to the inquiry. Without any concern, everybody decided to sign the contract. The expected research outcome and when it will be done for 
their analysis and the researcher's contact details were also given. This full ethical process made them feel satisfied and relieved to answer all questions without any disadvantages.

\section{Results and Discussion}

We highlighted several significant findings, based on the interviews, that emerged from the outcome of this research. This perspective was used to establish ideas about how the approach to IoTbased start-ups in Indonesia would best foster their innovation. The results were often used as a framework for proposing variables that support and hinder start-ups from leveraging their competitive advantage. A summary of the results is given in Figure 1 below. In this figure, all concepts and themes that arise from the data are given.

Figure 1. Dimension and Factors for IoT-based start-ups in Indonesia to support their innovation
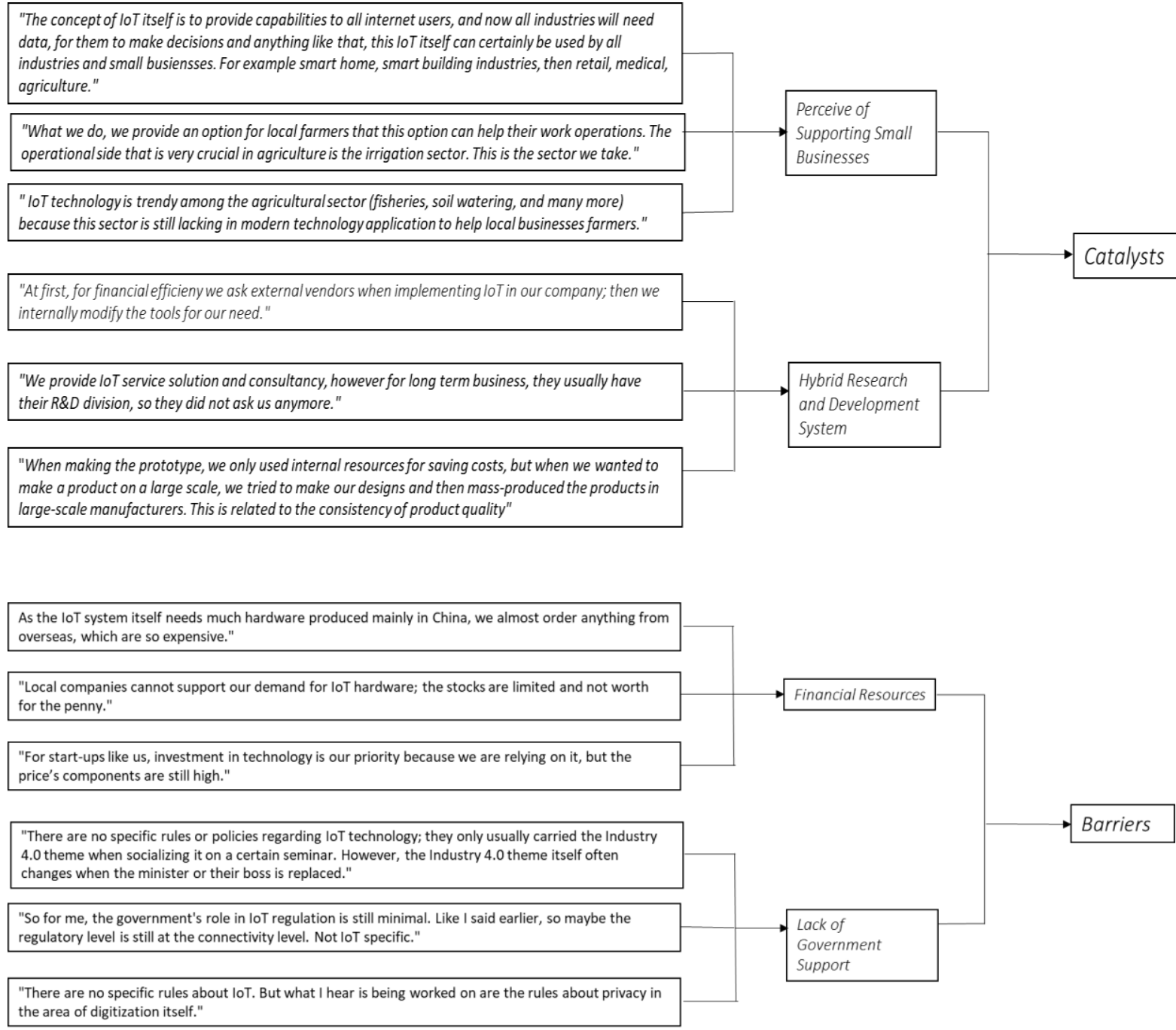


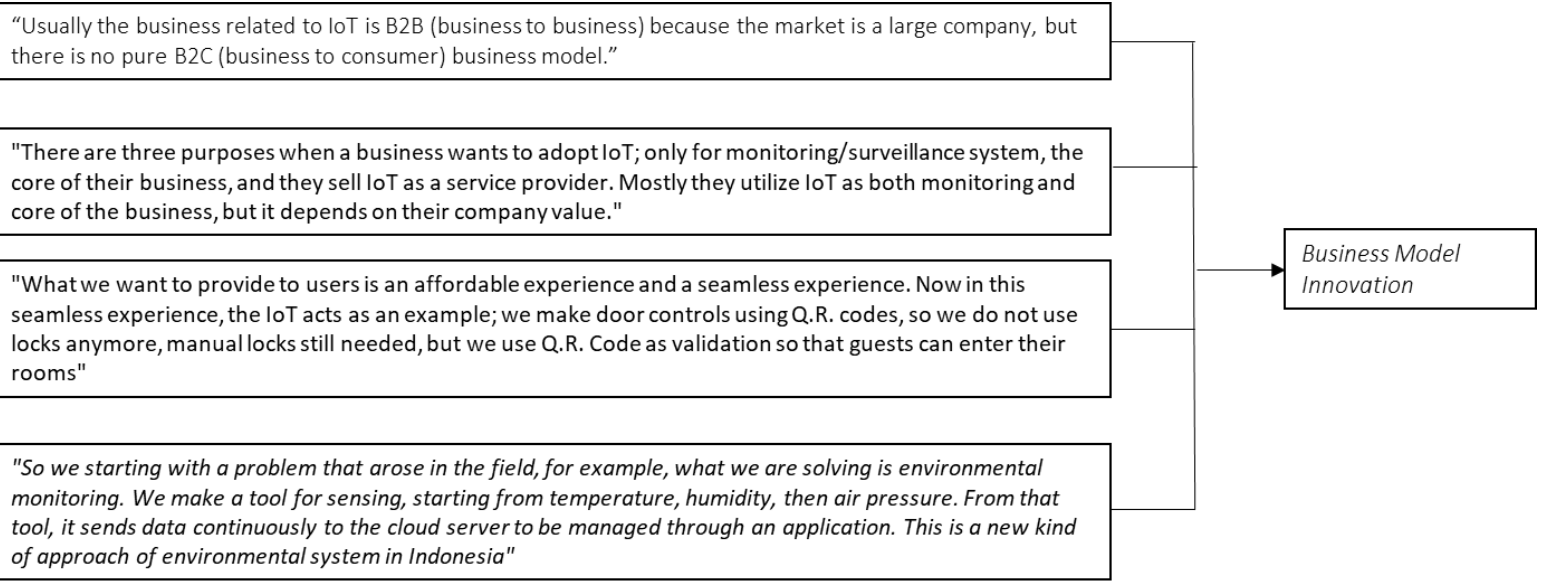

Based on the results, this study generates how the condition of IoT-based start-ups in Indonesia, which can foster their innovation, financial resources \& government role as the barriers that hinder their innovation, perceive of supporting local business \& hybrid R\&D (research and development) as the catalysts for IoT-based start-ups to innovate. The IoT-based start-ups in Indonesia seek to innovate their business model first to determine value proposition, customer segment, and channeling, leading to innovation performance.

Figure 2. Conceptual Model for IoT-based start-ups in Indonesia to support their innovation

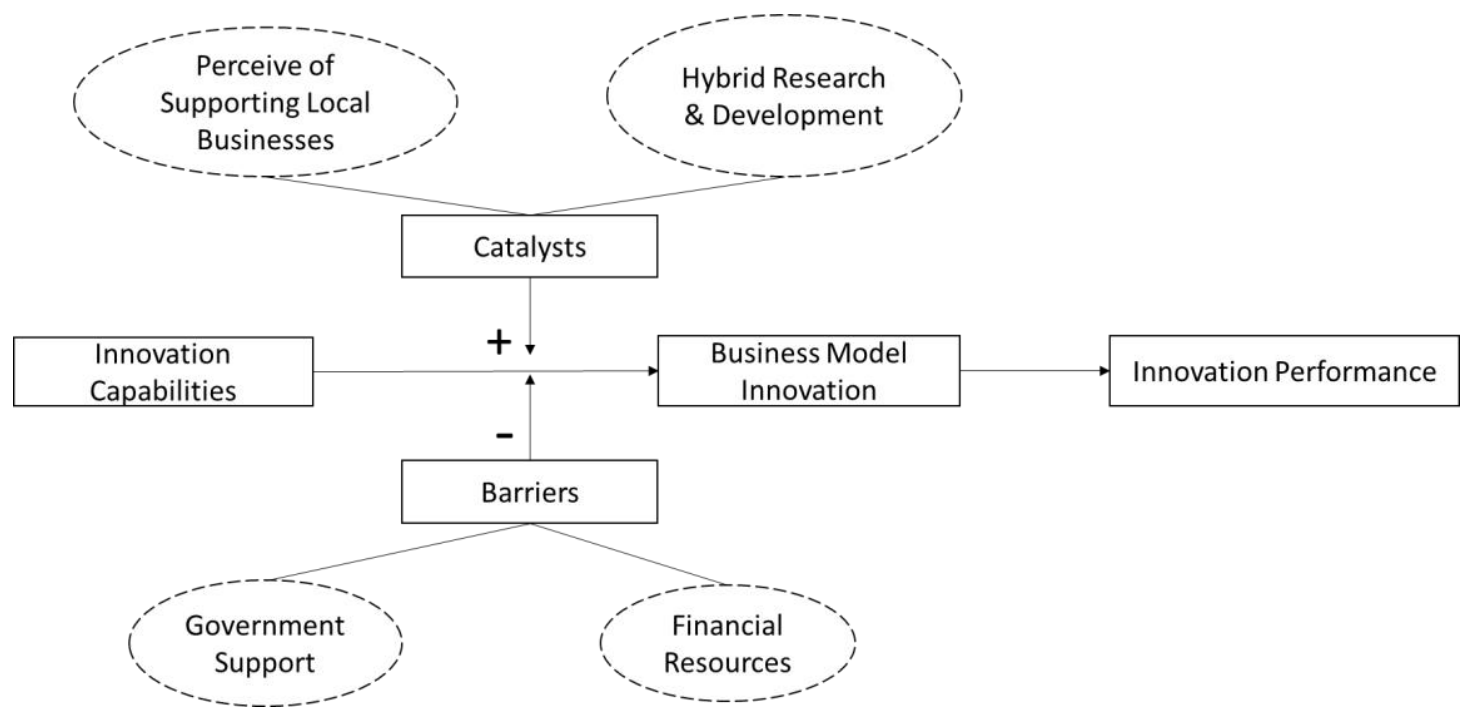

\subsection{Catalyst}

\subsubsection{Perceiving of Supporting Small Businesses}

It is not just about making profits that investors are worried. Many people have already invested all their resources and seek to build social and environmental interests to support small businesses. Social impact-based start-ups commit to meaningful social and environmental effects, thus producing future financial returns. (Cacciolatti, Rosli, Ruiz-Alba, \& Chang, 2020). The results showed that most start-ups are encouraged by local small businesses to use IoT to increase their efficiency and effectiveness, mostly small businesses in the agricultural sector. The start-ups also act as proactive adopters and actively involved in supporting and equipping the local small businesses. Industry 4.0 is costly to introduce and difficult for many smaller businesses; it can be a viable choice for start-ups to build solutions for small businesses. Therefore, this phenomenon provides opportunities for proactive 
adopters to pursue technologies across value creation, distribution, and capture in all three business model components (Müller, Buliga, \& Voigt, 2018). This supported by the interviewee:

"The concept of IoT itself is to provide capabilities to all internet users, and now all industries will need data, for them to make decisions and anything like that, this IoT itself can certainly be used by all industries and supporting small businesses. For example, smart home, smart building industries, then retail, medical, agriculture." (S5)

"What we do, we provide an option for local farmers that this option can help their work operations. The operational side that is very crucial in agriculture is the irrigation sector. This is the sector we take." (S3)

"IoT technology is trendy among the agricultural sector (fisheries, soil watering, and many more) because this sector is still lacking in modern technology application to help a local business like farmers." (S1)

Supporting SMEs is one factor that makes IoT-based start-ups innovate; this makes start-ups generally become intermediaries between industrial technology 4.0 and local SMEs in Indonesia. In general, these start-ups help with IoT technology to help problems encountered by small, agriculturebased businesses such as shrimp ponds, chicken farms, or automatic irrigation systems. They act as providers of hardware and software, which will later be lent to the business owner. They are also responsible for assisting these SMEs because their employees are generally not used to working with advanced technology such as IoT. The exciting thing about this finding is that even though IoT is a disruptive innovation (Caputo, Scuotto, Carayannis, \& Cillo, 2018), it does not disrupt the business as a whole because it does not directly disrupt the existing businesses; it helps SMEs to be more active in applying Industry 4.0 technology and increasing their productivity.

4.1.2. Hybrid Research and Development System (RED)

To introduce new products and processes, some enterprises focus solely on in-house R\&D. In order to access the global expertise, share the challenges and costs of innovation with other companies and improve the innovation process, other businesses are more outward-oriented and enter into R\&D partnership agreements. There are various organizations with which businesses may partner to undertake R\&D ventures. Competitors, employers, suppliers, universities, research institutes, and experts are included (Peeters \& Van Pottelsberghe De La Potterie, 2006). The results showed that the R\&D system in IoT-based start-ups in Indonesia is a hybrid system: combining external and internal resources. They learned first the technology from experts and asked for some advice, and finally, they make their R\&D division for further innovation. Interviewee's support this:

"At first, for financial efficiency, we ask external vendors when implementing IoT in our company; then we internally modify the tools for our need." (S2)

"We provide IoT service solution and consultancy, however for long term business, they usually have their $R \mathcal{E D}$ division, so they did not ask us anymore." (S9)

"There is an operation team that works with third parties related to the network activities." (S3)

"When making the prototype, we only used internal resources for saving costs, but when we wanted to make a product on a large scale, we tried to make our designs and then mass-produced the products in large-scale manufacturers. This is related to the consistency of product quality" (S6)

The second thing that becomes a catalyst in IoT-based start-ups for innovation is the hybrid research and development system. As it is known, the main component of IoT is hardware that contains sensors and functions to capture data and software that functions to process data and provide data to the owner of the device. Making IoT-based tools is not easy and cheap; it needs continuous R\&D both for hardware and software components. Start-ups generally have problems, namely limited operations, because the human resources at start-ups are usually small to reduce expenses (Ries, 2012). To overcome this problem, the R\&D department in start-ups involves external elements such as incumbent companies that use IoT, independent consultants, and even final-year students who know machines and telecommunications. R\&D collaboration with incumbent companies can increase both parties' trust so that the incumbent companies will not be disrupted even though the start-up has similar technology to them. Incumbent companies also give start-ups projects in the IoT field to solve their problems because the company knows the potential of IoT can increase their effectiveness and efficiency drastically. 


\subsection{Barriers}

\subsubsection{Financial Resources}

A start-up is traditionally defined as a newly established private company with a small business coverage area. They seek additional funding from venture capitalists as they build their businesses while developing their idea. Start-up investors primarily buy their investment from a part of the company. They invest money in return for equity: a percentage of its assets and potential earnings (Brikman, 2016). The results showed that the lack of funding support in this sector causes the innovation to slow down. Interviewees support this:

As the IoT system itself needs much hardware produced mainly in China, we almost order anything from overseas, which are so expensive." (S2)

"Local companies cannot support our demand for IoT hardware; the stocks are limited and not worth for the penny." (S1)

"For start-ups like us, investment in technology is our priority because we are relying on it, but the price's components are still high." (S3)

"Currently, because we are still making products with small quantities, the components are still from Indonesia, but for other well-established start-ups, I hear that they take their components from abroad, especially from China. Because the prices are reasonable." (S10)

Limited funding or financial resources is also a 'classic' problem in developing technology-based start-ups because start-ups are formed with few human resources, limited operational activities, and enter into an unclear niche market. To get around this, start-ups have the lean methodology to minimize expenses but can still produce prototypes that the user will give feedback (Brikman, 2016; Ries, 2012). Technology-based start-ups such as IoT require large funds because they provide a platform for clients and lend hardware tools as the main component. In Indonesia, hardware-specific to IoT is still rare, so start-ups use more imported components, especially from China, to meet their needs. Import costs that are not cheap create limitations in production, which can hinder product innovation for IoT-based start-ups in Indonesia.

\subsubsection{Lack of Government Support}

Government policies play a significant role in facilitating the start-up ecosystem for accessing information, tools, people, and other resources. Just like Silicon Valley in America, the centralized start-up ecosystem leads to faster cycles of learning everywhere and finally leads to innovation. The security and privacy issues that could emerge with IoT implementation also need national attention to prevent future problems (Sakhnini, Karimipour, Dehghantanha, Parizi, \& Srivastava, 2019). The results showed that the government's role in the IoT sector is not significant as they are giving little attention to it. Interviewees support this:

"There are no specific rules or policies regarding IoT technology; they only usually carried the Industry 4.0 theme when socializing it on a certain seminar. However, the Industry 4.0 theme itself often changes when the minister or their boss is replaced." (S1)

"They (government) mainly support the industry, especially the agriculture sector, by asking us to monitor what kind of crops are planted in each area. The policies about the technology itself are still lacking." (S2)

"From the Ministry of Communication and Information itself, the regulations will be in which sector related to this IoT. However, it is not specific yet, so it is used for industries related to this IoT or just to form this IoT ecosystem. So the regulations have indeed been formulated as fundamentals, but they do not cover all problems or have not solved all the problems to create an IoT industrial ecosystem." (S7).

"So for me, the government's role in IoT regulation is still minimal. Like I said earlier, so maybe the regulatory level is still at the connectivity level. Not IoT specific." (S8) 
"There are no specific rules about IoT. But what I hear is being worked on are the rules about privacy in the area of digitization itself." (S10)

Government support is one of the main barriers to IoT-based start-ups to innovate. Although the government has created a particular platform for start-ups to compete, they consider that the government's regulation role is more important because the existing regulations are still general, not specific to IoT. IoT specific regulations are related to data security because the automation system brought by IoT will make data abundant, and if there is no regulation, this data can be used by irresponsible parties such as hackers or competitors (Lo \& Campos, 2018; Sakhnini et al., 2019), especially with the establishment of a hybrid R\&D allowing for data in IoT-based companies are more exposed.

\subsection{Business Model Innovation}

In reality, business model innovations are becoming highly important. In the following three years, 98 percent of the CEOs interviewed reported that their company will pursue comprehensive (69 percent) or modest (29 percent) business model innovation. Companies must adapt and develop in any dimension in order to be successful in periods of turmoil. Mere advances in the product and method are seen as inadequate. The new market conditions require firms to modify their whole way of doing activities (Bucherer \& Uckelmann, 2011). The results showed that most of the business models of IoT still in a business-to-business context, however in the future, start-ups want to expand their wings to make IoT acceptable to individual customers.

"Usually the business related to IoT is B2B (business to business) because the market is a large company, but there is no pure B2C (business to consumer) business model." (S8)

One of the essential elements in generating business model innovation for industry 4.0 is the value proposition because the data that the IoT instantly creates will become a significant source of value creation and, therefore, a value proposition. This value involves information made possible only by the technologies of the Internet of Things and the connection of existing data with physical products (Bucherer \& Uckelmann, 2011; Metallo, Agrifoglio, Schiavone, \& Mueller, 2018).

In order to grow their businesses, start-ups have a single opportunity to respond to this demand. It helped start-ups to stand out from established rivals and to disrupt an entire market sometimes. Putting a value proposition at the core of the business also drives the actions and guarantees uniqueness. If a purpose is at the heart of the business, consumers can connect with it and generate positive social change at any point of contact. By welcoming people to companies' world', companies inspire them to contribute to companies' mission, which can turn people from once, consumers into lifelong customers (Ammirato et al., 2019). This supported by the interviewee:

"There are three purposes when a business wants to adopt IoT; only for monitoring/surveillance system, the core of their business, and they sell IoT as a service provider. Mostly they utilize IoT as both monitoring and core of the business, but it depends on their company value." (S4)

"What we want to provide to users is an affordable experience and a seamless experience. Now in this seamless experience, the IoT acts as an example; we make door controls using Q.R. codes, so we do not use locks anymore, manual locks still needed, but we use Q.R. Code as validation so that guests can enter their rooms". (S5)

"So we starting with a problem that arose in the field, for example, what we are solving is environmental monitoring. So if in the chicken farming industry, the chicken farming industry is also an industry that is 24 hours non-stop, the chickens must continue to be monitored. We make a tool for sensing, starting from temperature, humidity, then air pressure. From that tool, it sends data continuously to the cloud server to be managed through an application. This is a new kind of approach of environmental system in Indonesia". (S6)

Business model innovation is vital in IoT-based start-ups because it is relatively new in Indonesia and is commonly used in large companies. Interview results show that most start-ups put their value proposition as a 'bridge' between SMEs and IoT technology; therefore, adjustments are also needed to channel and customer segments before innovating in their products and services. The growth of the 
internet as the backbone of IoT has become the driving point why the business model is essential (Teece, 2010). There are three kinds of activities from the interview when a business wants to adopt IoT; only for monitoring/surveillance system, as the core of their business, and they sell IoT as a platform service provider. Most of the start-ups interviewed by authors utilized IoT as the core of the business and sell it as a platform service provider.

For the customer segment, IoT-based start-ups use a business-to-business (b2b) concept to sell products and services to fellow business owners. However, start-ups are also thinking about the possibility of a business-to-consumer (b2c) concept because IoT technology's advancement makes commercialization easier for households to enter. For example, smart home equipment using the IoT system is starting to be used by people in developed countries (Hartmann \& Halecker, 2015). Since the technology itself does not have any single objective meaning, technology's economic potential stays dormant until a new business model commercializes it in some manner (Chesbrough, 2010). Therefore, with the rapid development of internet users in Indonesia, the b2c concept will be profitable for IoTbased enterprises in the future.

\section{Conclusions}

The study examined and identified the innovation path carried by IoT-based start-ups in Indonesia. It results in five primary factors for them to innovate: financial resources, government role, perception for supporting small businesses, hybrid research and development, and innovating their business model. It also highlights the innovation mostly carried by both internal and external teams to make a substantial social impact for small businesses. The Indonesian government also should support innovation support in IoT-based start-ups by its specific regulations and policies and channeling angel investors or big corporations investing in them. Our study contributes to a relatively new research area, which involves IoT-based start-ups, particularly in Indonesia. We highlight the impacts of IoT for the strategic nature of business models, such as the involvement of local small businesses in Indonesia in catching the utility of IoT with the assistance of start-ups, information-driven value propositions focused on technology innovations for consumers and end-users, and the role of value networks for IoT market innovations aimed at individual end-users in the future. This study could be useful for businesses related to IoT to forecast the technological trajectory, which will lead to a better business model in the future. This study is also useful for government or policymaker to make them realize the importance of IoT's potential and be interested in IoT usage, and finally, support it with its regulation and enhancing the Industry 4.0 ecosystem. Since the IoT adoption in Indonesia is relatively new and the research regarding its business aspect is still lacking; therefore, this research could have answered the question related to how IoT-based businesses use the technology to innovate and keep the enterprises sustain in the future with their innovation path. However, this research still has limitations as not all the business aspects of IoT-based businesses are discussed here, such as their marketing strategy. Therefore, future research agendas could assess how they market their products since they use industrial-grade technology, leading to niche-market customers.

Author Contributions: Conceptualization, TRF and WD.; methodology, TRF and WD.; validation, TRF and WD.; formal analysis, TRF.; investigation, TRF.; resources, TRF.; data curation, TRF.; writing-original draft preparation, TRF; writing-review and editing, TRF.; visualization, TRF.; supervision, WD.; project administration, TRF. All authors have read and agreed to the published version of the manuscript.

Funding: This research received no external funding

Conflicts of Interest: The authors declare no conflict of interest

\section{References}

Ammirato, S., Sofo, F., Felicetti, A. M., \& Raso, C. (2019). A methodology to support the adoption of IoT innovation and its application to the Italian bank branch security context. European Journal of Innovation Management, 22(1), 146-174. https://doi.org/10.1108/EJIM-03-2018-0058 
Ashton, K. (2009). That “Internet of Things" Thing. RFID Journal, 4986. https://doi.org/10.1145/2967977

Balaji, M. S., \& Roy, S. K. (2017). Value co-creation with internet of things technology in the retail industry. Journal of Marketing Management, 33(1-2), 7-31. https://doi.org/10.1080/0267257X.2016.1217914

Brikman, Y. (2016). Hello, Start-up: A Programmer's Guide to Building Products, Technologies, and Teams. North Sebastopol, CA: O’Reilly Media, Inc.

Bucherer, E., \& Uckelmann, D. (2011). Business Models for the Internet of Things. In Architecting the Internet of Things (pp. 253-277). https://doi.org/10.1007/978-3-642-19157-2_10

Burke, M. E., O'Callaghan, S., \& Quigley, M. (2013). The business of digital storytelling: Augmenting information systems with Q.R. codes. Journal of Systems and Information Technology, 15(4), 347-367. https://doi.org/10.1108/JSIT-04-2013-0009

Cacciolatti, L., Rosli, A., Ruiz-Alba, J. L., \& Chang, J. (2020). Strategic alliances and firm performance in start-ups with a social mission. Journal of Business Research, 106(August 2019), 106-117. https://doi.org/10.1016/j.jbusres.2019.08.047

Caputo, F., Scuotto, V., Carayannis, E., \& Cillo, V. (2018). Intertwining the internet of things and consumers' behaviour science: Future promises for businesses. Technological Forecasting and Social Change, 136(March 2017), 277-284. https://doi.org/10.1016/j.techfore.2018.03.019

Chesbrough, H. (2010). Business model innovation: Opportunities and barriers. Long Range Planning, 43(2-3), 354363. https://doi.org/10.1016/j.lrp.2009.07.010

Creswell, J. W. (2007). Qualitative enquiry \& research design, choosing among five approaches. In Book.

Dai, Y., Xia, D., Zhou, Y., \& Xue, L. (2014). The innovation Path of the Chinese Wind Power Industry (No. No. 32/2014). Bonn.

Das, K., Gryseels, M., Sudhir, P., \& Tan, K. T. (2016). Unlocking Indonesia's Digital Opportunity. McKinsey E Company, (October), 1-28. Retrieved from https://www.mckinsey.com/ /media/McKinsey/Locations/Asia/Indonesia/Our Insights/Unlocking Indonesias digital opportunity/Unlocking_Indonesias_digital_opportunity.ashx

Dijkman, R. M., Sprenkels, B., Peeters, T., \& Janssen, A. (2015). Business models for the Internet of Things. International Journal of Information Management, 35(6), 672-678. https://doi.org/10.1016/j.ijinfomgt.2015.07.008

Dosi, G. (1982). Technological paradigms and technological trajectories. A suggested interpretation of the determinants and directions of technical change. Research Policy, 11(3), 147-162. https://doi.org/10.1016/00487333(82)90016-6

Dwianto, M., \& Dhewanto, W. (2015). Barriers in Implementing the Lean Startup Methodology in Indonesia Case Study of B2B Startup. Procedia - Social and Behavioral Sciences, 169(August 2014), 23-30. https://doi.org/10.1016/j.sbspro.2015.01.282

Eisenhardt, K. M. (1989). Building Theories from Case Study Research Published by : Academy of Management Stable. The Academy of Management Review, 14(4), 532-550.

Ghobakhloo, M., \& Ching, N. T. (2019). Adoption of digital technologies of smart manufacturing in SMEs. Journal of Industrial Information Integration, 16(January), 100107. https://doi.org/10.1016/j.jii.2019.100107

Hartmann, M., \& Halecker, B. (2015). Management of Innovation in the Industrial Internet of Things. XXVI ISPIM Conference - Shaping the Frontiers of Innovation Management in Budapest, Hungary on 14-17 June 2015, (June), 117. Retrieved from https://www.researchgate.net/publication/277870196

Kemenperin. (2018). Making Indonesia 4.0. Retrieved from https://www.kemenperin.go.id/download/18384

Kiel, D., Arnold, C., \& Voigt, K. I. (2017). The influence of the Industrial Internet of Things on business models of established manufacturing companies - A business-level perspective. Technovation, 68(July), 4-19. https://doi.org/10.1016/j.technovation.2017.09.003

Kirner, E., Kinkel, S., \& Jaeger, A. (2009). Innovation paths and the innovation performance of low-technology firms - An empirical analysis of German industry. Research Policy, 38, 447-458. https://doi.org/10.1016/j.respol.2008.10.011

Kohler, T. (2016). Corporate accelerators : Building bridges between corporations and start-ups. Business Horizons, 59(3), 347-357. https://doi.org/10.1016/j.bushor.2016.01.008

Krotov, V. (2017). The Internet of Things and new business opportunities. Business Horizons, 60(6), 831-841. https://doi.org/10.1016/j.bushor.2017.07.009

Lasi, H., Fettke, P., Kemper, H. G., Feld, T., \& Hoffmann, M. (2014). Industry 4.0. Business and Information Systems Engineering, 6(4), 239-242. https://doi.org/10.1007/s12599-014-0334-4 
Lee, I. (2019). The Internet of Things for enterprises: An ecosystem, architecture, and IoT service business model. Internet of Things, 7(2019), 100078. https://doi.org/10.1016/j.iot.2019.100078

Lee, I., \& Lee, K. (2015). The Internet of Things (IoT): Applications, investments, and challenges for enterprises. Business Horizons, 58(4), 431-440. https://doi.org/10.1016/j.bushor.2015.03.008

Lema, R., Sagar, A., \& Zhou, Y. (2016). Convergence or divergence? Wind power innovation paths in Europe and Asia. Science and Public Policy, 43(3), 400-413. https://doi.org/10.1093/scipol/scv049

Leminen, S., Rajahonka, M., Wendelin, R., \& Westerlund, M. (2020). Industrial internet of things business models in the machine-to-machine context. Industrial Marketing Management, 84(August 2019), $298-311$. https://doi.org/10.1016/j.indmarman.2019.08.008

Li, G., Hou, Y., \& Wu, A. (2017). Fourth Industrial Revolution: technological drivers, impacts and coping methods. Chinese Geographical Science, 27(4), 626-637. https://doi.org/10.1007/s11769-017-0890-x

Li, S., Xu, L. Da, \& Zhao, S. (2015). The internet of things: a survey. Information Systems Frontiers, 17(2), $243-259$. https://doi.org/10.1007/s10796-014-9492-7

Lo, F. Y., \& Campos, N. (2018). Blending Internet-of-Things (IoT) solutions into relationship marketing strategies. Technological Forecasting and Social Change, 137(April), 10-18. https://doi.org/10.1016/j.techfore.2018.09.029

Lu, Y., Papagiannidis, S., \& Alamanos, E. (2018). Internet of things: A systematic review of the business literature from the user and organisational perspectives. Technological Forecasting and Social Change, 136(April 2017), 285-297. https://doi.org/10.1016/j.techfore.2018.01.022

Maulana, A., Sucahyo, Y. G., Ruldeviyani, Y., \& Gandhi, A. (2019). Requirements for platform-based start-up survival: A qualitative exploratory study. 2018 International Conference on Advanced Computer Science and Information Systems, ICACSIS 2018, 137-142. https://doi.org/10.1109/ICACSIS.2018.8618231

Melegati, J., Goldman, A., \& Paulo, S. (2016). Requirements Engineering in Software Start-ups : a Grounded Theory approach. 2nd International Workshop on Software Startups.

Mercandetti, F., Larbig, C., Tuozzo, V., \& Steiner, T. (2017). Innovation by Collaboration between Start-ups and SMEs in Switzerland. Technology Innovation Management Review, 7(12), 23-31. https://doi.org/10.22215/timreview/1125

Metallo, C., Agrifoglio, R., Schiavone, F., \& Mueller, J. (2018). Understanding business model in the Internet of Things industry. Technological Forecasting and Social Change, 136(February 2017), 298-306. https://doi.org/10.1016/j.techfore.2018.01.020

Moroni, I., Arruda, A., \& Araujo, K. (2015). The design and technological innovation : how to understand the growth of start-ups companies in competitive business environment. 6th International Conference on Applied Human Factors and Ergonomics (AHFE 2015) and the Affiliated Conferences, AHFE 2015, 3, $2199-2204$. https://doi.org/10.1016/j.promfg.2015.07.361

Müller, J. M. (2019). Business model innovation in small- and medium-sized enterprises: Strategies for industry 4.0 providers and users. Journal of Manufacturing Technology Management, 30(8), 1127-1142. https://doi.org/10.1108/JMTM-01-2018-0008

Müller, J. M., Buliga, O., \& Voigt, K. I. (2018). Fortune favors the prepared: How SMEs approach business model innovations in Industry 4.0. Technological Forecasting and Social Change, 132(September 2017), 2-17. https://doi.org/10.1016/j.techfore.2017.12.019

Nurcahyo, R., Akbar, M. I., \& Gabriel, D. S. (2018). Characteristics of start-up company and its strategy: Analysis of Indonesia fashion start-up companies. International Journal of Engineering and Technology(UAE), 7(2), 4447. https://doi.org/10.14419/ijet.v7i2.34.13908

Peeters, C., \& Van Pottelsberghe De La Potterie, B. (2006). Innovation strategy and the patenting behavior of firms. Journal of Evolutionary Economics, 16(1-2), 109-135. https://doi.org/10.1007/s00191-005-0010-4

Prince, K., Barrett, M., \& Oborn, E. (2014). Dialogical strategies for orchestrating strategic innovation networks: The case of the Internet of Things. Information and Organization, 24(2), 106-127. https://doi.org/10.1016/j.infoandorg.2014.05.001

Quigley, M., \& Burke, M. (2013). Low-cost internet of things digital technology adoption in SMEs. International Journal of Management Practice, 6(2), 153-164. https://doi.org/10.1504/IJMP.2013.055828

Raatikainen, M., Komssi, M., Kiljander, H., Hokkanen, L., Märijärvi, J., \& Mohout, O. (2016). Eight Paths of Innovations in a Lean Startup Manner: A Case Study. In Product-Focused Software Process Improvement (PROFES) (Vol. 10027, pp. 198-214). https://doi.org/10.1007/978-3-319-49094-6 
Ries, E. (2012). The Lean Startup: How Today's Entrepreneurs Use Continuous Innovation to Create Radically Successful Businesses. https://doi.org/10.1111/j.1540-5885.2012.00920_2.x

Robinson, D. K. R., Lagnau, A., \& Boon, W. P. C. (2019). Innovation pathways in additive manufacturing: Methods for tracing emerging and branching paths from rapid prototyping to alternative applications. Technological Forecasting and Social Change, 146(January), 733-750. https://doi.org/10.1016/j.techfore.2018.07.012

Sakhnini, J., Karimipour, H., Dehghantanha, A., Parizi, R. M., \& Srivastava, G. (2019). Security aspects of Internet of Things aided smart grids: A bibliometric survey. Internet of Things, (xxxx), 100111. https://doi.org/10.1016/j.iot.2019.100111

Saunders, M., Lewis, P., \& Thornhill, A. (2009). Research Methods for Business Students. 5th ed. In Pearson Education Limited. Essex CM20 2JE. https://doi.org/10.1007/s13398-014-0173-7.2

Shin, D.-I. (2017). An exploratory study of innovation strategies of the internet of things SMEs in South Korea. Asia Pacific Journal of Innovation and Entrepreneurship, 11(2), 171-189. https://doi.org/10.1108/apjie-08-2017-025

Startup4industry. (2020). START-UP TECH PROVIDER 4 INDUSTRY. Retrieved from https://www.startup4industry.id

Stubner, S., Wulf, T., \& Hungenberg, H. (2007). Management Support and the Performance of Entrepreneurial Start-ups: An Empirical Analysis of Newly Founded Companies in Germany. Schmalenbach Business Review, 59(2), 138-159. https://doi.org/10.1007/BF03396745

Suppatvech, C., Godsell, J., \& Day, S. (2019). The roles of internet of things technology in enabling servitized business models: A systematic literature review. Industrial Marketing Management, 82(February), 70-86. https://doi.org/10.1016/j.indmarman.2019.02.016

Teece, D. J. (2010). Business models, business strategy and innovation. Long Range Planning, 43(2-3), $172-194$. https://doi.org/10.1016/j.lrp.2009.07.003

Tuan, M. N. D., Thanh, N. N., \& Tuan, L. Le. (2019). Applying a mindfulness-based reliability strategy to the Internet of Things in healthcare - A business model in the Vietnamese market. Technological Forecasting and Social Change, 140(September 2018), 54-68. https://doi.org/10.1016/j.techfore.2018.10.024

World Intellectual Property Organization. (2020). Global Innovation Index 2020. Retrieved from https://www.wipo.int/global_innovation_index/en/2020/

Yin, R. K. (2003). Case Study Research: Design and Methods (Vol. 3). https://doi.org/10.1300/J145v03n03_07

Zaidi, M. F. A., \& Belal, H. . (2019). A Preliminary Study To Understand the SMEs' Readiness on IoT in a Preliminary Study To Understand the SMEs' Readiness on IoT in Malaysia. International Journal of Accounting, Finance and Business (IJAFB), 4(19), 01-12.

(C) 2020 by the authors. This article is an open-access article distributed under the terms and conditions of the Creative Commons Attribution (CC BY) license (http://creativecommons.org/licenses/by/4.0/). 